\title{
Comment
}

\section{Comment on: Akasofu, S.-I. On the Present Halting of Global Warming. Climate 2013, 1, 4-11}

\author{
Dana A. Nuccitelli ${ }^{1}$, John P. Abraham ${ }^{2, *}$, Rasmus E. Benestad ${ }^{3}$ and Scott A. Mandia ${ }^{4}$ \\ 1 Skeptical Science, Brisbane, Queensland 4072, Australia; E-Mail: dana1981@yahoo.com \\ 2 University of St. Thomas, School of Engineering, 2115 Summit Ave, St. Paul, MN 5105, USA \\ 3 Norwegian Meteorological Institute, P.O. Box 43 Blindern, Oslo 0313, Norway; \\ E-Mail: rasmus.benestad@gmail.com \\ 4 Suffolk County Community College, 533 College Rd, Selden, NY 11784, USA; \\ E-Mail: mandias@sunysuffolk.edu
}

* Author to whom correspondence should be addressed; E-Mail: jpabraham@ stthomas.edu;

Tel.: +1-651-962-5766; Fax: +1-651-962-6419.

Received: 13 August 2013 /Accepted: 13 September 2013 / Published: 19 September 2013

\begin{abstract}
A recent article which has set forth new interpretations of Earth's recent climate history has included some questions of authentic scientific inquiry, particularly related to the impact of ocean oscillations on atmospheric temperatures. In fact, this very issue is currently being investigated by multiple research groups. On the other hand, the claim that a two-century linear temperature increase is a recovery from a recent cool period is not supported by the data. Furthermore, this thermal recovery hypothesis is not connected to any physical phenomenon; rather it is a result of a simplistic and incorrect curve-fitting operation. Other errors in the article are: the claim that the heating of the Earth has halted, misunderstanding of the relationship between carbon dioxide concentration and the resultant radiative forcing, and a failure to account for forcings other than carbon dioxide (such as other greenhouse gases, atmospheric aerosols, land use changes, etc.). Each of these errors brings serious question to the conclusions drawn in the referenced article. The simultaneous occurrence of all of these errors in a single study guarantees that its conclusions cannot be supported and, in fact, are demonstrably incorrect.
\end{abstract}

Keywords: global warming; climate change; carbon dioxide; greenhouse gases; thermal recovery; natural climate fluctuations; ocean oscillations 


\section{Introduction}

Throughout the history of Earth science studies, various natural and anthropogenic causes of climate change have been proposed and tested by established scientific methods. The separate identification and quantification of both human and natural climate forces is an area of ongoing research. Some summarizing documents, such as the Intergovernmental Panel on Climate Change reports [1] have tried to quantify the impact of humans on the climate; more recent work has come to even stronger conclusions that humans are a dominant climate force today $[2,3]$.

Nevertheless, occasionally papers appear which present a contrarian view of the human impact on the Earth's climate. Often, these papers suggest natural variability is the most significant cause of the rapid changes we are now observing in the Earth's climate system.

Recently, a paper of this sort was published in the present journal [4], which makes some claims that, if true, would overturn decades of climate research. Unfortunately, it has been found that significant errors exist in [4], which make its conclusions untenable. Furthermore, the text of [4] does not significantly disclose methods or data sources so that it challenges the reader to interpret the findings contained therein.

Here, we identify some of the key errors in [4] and also describe areas in which the presentation is inadequate. Our work shows that the conclusions of [4] are without merit and, in some cases, demonstrably wrong.

The central hypothesis articulated in [4] is that recent climate change is a superposition of two trends: (1) a two-century long linear temperature increase which is described as a "recovery" from the Little Ice Ago (LIA) and (2) a multi-decadal oscillation related to the Pacific Decadal Oscillation (PDO). By deconstructing the temperature record into linear and oscillating components, the author of [4] concludes that the Earth is headed for a near-term temperature decrease that will last until approximately 2030 .

\section{Errors of Prior Publication}

While there are a number of errors in [4], here, only the most critical ones will be addressed, for sake of brevity. There is no particular ordering of importance; each of these errors is significant on its own.

\subsection{Lack of Physical Mechanisms}

The author describes the global mean surface temperature (GMST) record as partly a linear temperature increase caused by a recovery from the LIA. However, a recovery is not a cause and in fact, the author offers no physical mechanism that would reportedly cause such a temperature increase. The author also assumes the linear GMST warming trend will continue indefinitely, despite lacking any proposed physical cause. According the conservation of energy principle, only an energy imbalance at the top of the atmosphere (TOA) could cause a long-term GMST increase.

Even if there were some (hitherto unidentified) energy imbalance that occurred during the LIA, the Earth would relax to a new equilibrium temperature that would consist of rapid initial heating followed by slow heating as the new equilibrium is approached [5]. 
The exact opposite has been observed: a slow increase in GMST in the early 20th century, followed by more rapid temperature increases in recent decades. This observation strongly argues against relaxation from an LIA energy imbalance being responsible for the current global warming.

Furthermore, thermal systems do not contain "memory" of past climate states, as inferred by [4]. Changes to the total energy of the Earth system are dictated by present energy balances, not by prior climatic states.

\subsection{Claim of a Halt to Present Heating}

The status of the Earth energy balance, and the consequent heating, cooling, or stasis of its temperature can be determined in a number of mutually supporting ways. Perhaps the easiest is to measure changes of the energy stored in the Earth thermal reservoirs, principally the oceans, but also the cryosphere, land, and atmosphere.

There is a wealth of published studies that conclusively show the Earth thermal reservoirs are gaining heat. Among them are [6-17] which represent a small subset of available information. A careful review of the literature shows that not only are the Earth's oceans heating, but that the heating has generally increased in recent decades. It is found that heating rates from 1970-2012 are lower than rates measured from 1980-2012, which in turn are less than 1993-2012 rates. A recent paper summarizing current understanding of ocean heat content is [18].

Other studies, such as [19-21] have incorporated ocean heat content measurements along with other non-oceanic reservoir storage. They too conclude that the Earth is currently gaining energy (heating) with no halt or even deceleration.

Many studies have used satellites to measure the differences in incoming and outgoing radiation at TOA (e.g., [22,23]). Satellite missions such as Clouds and the Earth's Radiant Energy System (CERES) can provide measurements of sufficient accuracy and duration required to balance energy. TOA measurements show that the Earth is currently experiencing an energy imbalance (a net gain of thermal energy) and consequently heating.

The third way to estimate Earth energy imbalance is by thermosteric ocean expansion and associated sea-level rise. Other contributors to sea-level rise are increases in ocean mass through melting of land-based ice and changes in the global distribution of water. Climate scientists use these three methods to provide independent verification that the Earth is, in fact, unbalanced with respect to thermal energy.

The disclosure of continued sea level rise in [4] invalidates the claim that the Earth warming has halted. This claim is also invalidated by recent measurements of ocean heating or TOA radiation, as described in the foregoing. To the best knowledge of the authors, there are no studies that show the Earth is not currently gaining thermal energy and heating.

It appears that the claim of a halt to the Earth heating is based in part on an opinion article [24] that is strongly contradicted by an extensive body of peer-reviewed research, only some of which has been listed here. The claim for a halt to Earth heating furthermore cannot be determined solely by considering atmospheric temperatures; the atmosphere thermal reservoir is responsible for approximately $2 \%$ of heat uptake and is subject to significant short-term variability (e.g., ENSO) that in the short-term may mask long-term trends [1]. 


\subsection{Lack of a Two-Century Linear Temperature Increase}

Among the claims made in [4] were that a linear temperature increase has occurred over the past two centuries, with a superimposed cyclical GMST influence from the PDO. It is generally accepted that instrumental GMST records can be extended back to the 1850-1880 time period. There is no recognized repository of instrumental GMST data that predate $\sim 1850$. In support of our claim, Figure 1 in [4] begins circa 1850 and extends to near the present time - not a two-century duration.

Figure 1. Comparison of linear and quadratic temperature trendlines to HADCRUT4 GMST.

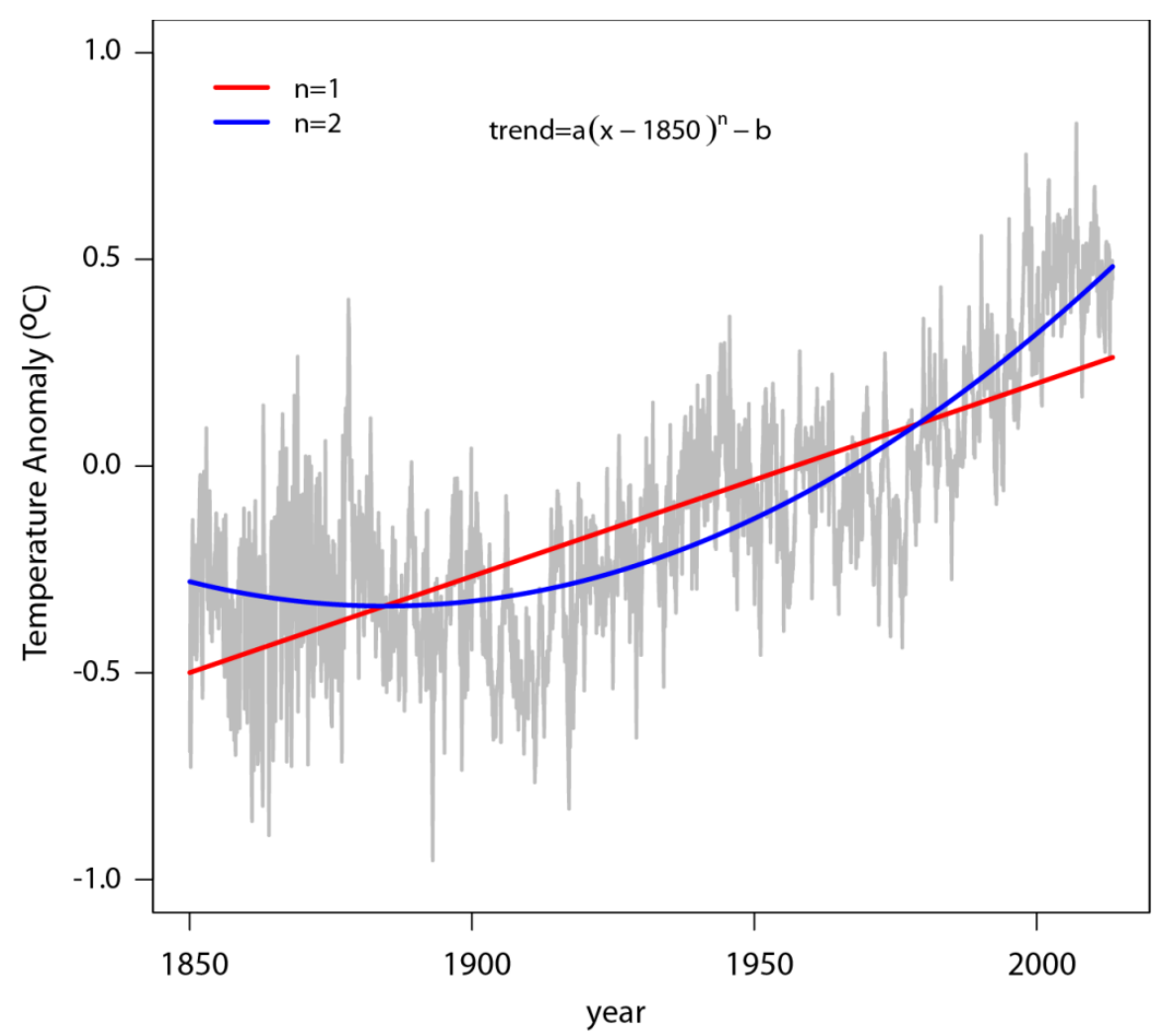

Temperature information further back into time must be gathered by natural proxy reconstruction. Proxy reconstructions are less certain than the instrumental record and their accuracy must be discussed when temperature trends are derived. While proxy temperature information was presented in [4], the accuracy and resolution of these proxies was not discussed. Further, the methodology of connecting proxy records to the instrumental record was not discussed.

Central to the claim of linear temperature increase is Figure 3 contained in [4]. The author states that "all these results clearly show near linear increases in temperature from about 1800-1850 to 2000." It is the responsibility of the author to mathematically show what is, in our opinion, not correct. To evaluate whether a non-linear trend line better fits the data, Figure 1 has been prepared that shows linear and quadratic trend lines fit to the 1850-2010 data. It is apparent that the quadratic fit yields significant improvements compared to the linear fit. Separate calculations of the trend line residuals confirm this visual conclusion. The present authors here note that even though higher order polynomials fit the data better than a linear choice, here too, no physical mechanism is applied. This is, in truth, a pure mathematical exercise and of little value interpreting climate physics. 
Our conclusion that a linear fit is inappropriate is reinforced by Figure 5 from [4]. That figure shows a callout box that superimposes a low quality linear approximation to actual temperature information (HADCRUT4), as in our Figure 1. The linear-fit conclusion is also contradicted by Figure 1 in [4], which shows a series of linear trend line fits to temperature data, extending back to approximately 1860. In the legend of the figure, the more recent trend line slopes are more positive which reflect a faster temperature increase in recent decades as opposed to a constant linear trend.

\subsection{Failure to Consider Many Known Climate Forcings}

Aside from the errors with quantitative information, as outlined in the preceding sections, the author of [4] makes severe errors of omission that demonstrate significant misunderstandings of the intricacies of the Earth's climate. Many factors, aside from carbon dioxide, influence the climate. Some factors are natural (solar variability, orbital changes, volcanoes, natural greenhouse gases, etc.) while others are human-caused (human-emitted greenhouse gases, land-use changes, aerosol production, etc.). The discussion of early 20th century temperature changes must include these other factors. For instance, it is currently believed that the early 20th century temperature increases had a number of instigators, among them increased solar activity and land use changes. In the middle part of the 20th century, anthropogenic emissions of aerosols are thought to be primarily responsible for a temporary cessation of heating. Other factors, such as changes to ocean temperature measurement systems and improvements to the worldwide network of atmospheric measuring capabilities impact the Earth's temperature record.

In the later part of the century, increases in greenhouse gases, particularly $\mathrm{CO}_{2}$ but also nitrous oxide, methane, CFCs, etc. have allowed the human greenhouse effect to play an increasingly dominant role in climate change.

The very simplified, and incorrect, attribution of temperature changes to $\mathrm{CO}_{2}$ as a rhetorical argument is short-sided and demonstrably incorrect.

\subsection{Mistaken Carbon Dioxide Forcing}

A final error is made in relation to the climate forcing caused by $\mathrm{CO}_{2}$. It is well known that the radiative forcing for greenhouse gas concentration changes is not linear with respect to the concentration [25]. For $\mathrm{CO}_{2}$ for instance, the radiative forcing varies with the log of the concentration. The claim in [4] that the presence of a linear increase in temperatures coinciding with a near quadratic increase in $\mathrm{CO}_{2}$ is not, as the author suggests, problematic (even if it were to be occurring).

A proper prediction of the rate of Earth temperature increase would require a knowledge of the rate of change of $\mathrm{CO}_{2}$ and other greenhouse gases, along with changes of other human and natural climate forcings.

\section{Conclusions}

While there are other serious shortcomings in [4], for sake of brevity, only some are mentioned here. These errors and misinterpretations lead readers to the mistaken conclusion that GMST can simply be constructed by superposition of a long-term linear trend and a multi-decadal oscillation. 
The most critical errors, which are reported here, include the lack of a physical mechanism which has caused the long-term GMST rise, the mistaken statement that global warming has halted, the poorly chosen linear approximation to the Earth's atmospheric temperature evolution, the failure to recognize climate forcings other than $\mathrm{CO}_{2}$, and the misunderstanding of the strength of $\mathrm{CO}_{2}$ as a greenhouse gas. Any one of these errors would render the conclusions drawn in [4] suspect.

It is reasonable, as the author suggests, to consider that the Earth's temperature variations that have a natural component related to multi-decadal ocean oscillations. It is also true that recent atmospheric temperature measurements have significantly slowed their increase compared to previous years. Exploration of the role of the PDO in moderating temperature increases and in distributing heat more efficiently to deep ocean zones is a useful and important endeavor. However, the method carried out in [4] makes errors of such gravity that the central conclusions cannot hold.

\section{Conflicts of Interest}

The authors declare no conflict of interest.

\section{References}

1. Intergovernmental Panel on Climate Change (IPCC). Climate Change 2007: The Physical Science Basis; Solomon, S., Qin, D., Manning, M., Chen, Z., Marquis, M., Averyt, K.B., Tignor, M., Miller, H.L., Eds.; Cambridge University Press: Cambridge, UK, 2007.

2. Gleckler, P.J.; Santer, B.D.; Domingues, C.M.; Pierce, D.W.; Barnett, T.P.; Church, J.A.; Taylor, K.E.; AchutaRao, K.M.; Boyer, T.P.; Ishii, M.; et al. Human-induced global ocean warming on multidecadal timescales. Nat. Clim. Chang. 2012, 2, 524-529.

3. Pierce, D.W.; Gleckler, P.J.; Barnett, T.P.; Santer, B.D.; Durack, P.J. The fingerprint of human-induced changes in the ocean's salinity and temperature fields. Geophys. Res. Lett. 2012, 39, doi:10.1029/2012GL053389.

4. Akasofu, S.-I. On the present halting of global warming. Climate 2013, 1, 4-11.

5. Hansen, J.; Nazarenko, L.; Ruedy, R.; Sato, M.; Willis, J.; Del Genio, A.; Koch, D.; Lacis, A.; Lo, K.; Menon, S.; et al. Earth's energy imbalance: Confirmation and implications. Science 2005, 308, 1431-1435.

6. Palmer, M.D.; Antonov, J.; Barker, P.; Bindoff, N.L.; Boyer, T.; Carson, M.; Domingues, C.M.; Gille, S.; Gleckler, P.; Good, S. Future Observations for Monitoring Global Ocean Heat Content. In Proceedings of the OceanObs' 09: Sustained Ocean Observations and Information for Society Conference, Venice, Italy, 21-25 September 2009; Hall, J., Harrison, D.E., Stammer, D., Eds.; ESA Publication WPP-306; Paris, France, 2010; Volume 2.

7. Lyman, J.M.; Good, S.A.; Gouretski, V.V.; Ishii, M.; Johnson, G.C.; Palmer, M.D.; Smith, D.M.; Willis, J.K. Robust warming of the global upper ocean. Nature 2010, 465, 334-337.

8. Ishii, M.; Kimoto, M. Reevaluation of historical ocean heat content variations with time-varying XBT and MBT depth bias corrections. J. Oceanogr. 2009, 65, 287-299.

9. Domingues, C.M.; Church, J.A.; White, N.J.; Gleckler, P.J.; Wijffels, S.E.; Barker, P.M.; Dunn, J.R. Improved estimates of upper-ocean warming and multi-decadal sea-level rise. Nature 2008, 453, 1090-1093. 
10. Levitus, S.; Antonov, J.; Boyer, T.P.; Stephens, C. Warming of the world ocean. Science 2000, 287, 2225-2229.

11. Levitus, S.; Antonov, J.; Wang, J.; Delworth, T.L.; Dixon, K.W.; Broccoli, A.J. Anthropogenic warming of the Earth's Climate System. Science 2001, 292, 267-270.

12. Levitus, S.; Antonov, J.; Boyer, T.P. Warming of the world ocean, 1955-2003. Geophys. Res. Lett. 2005, 32, doi:10.1029/2004GL021592.

13. Levitus, S.; Antonov, J.I.; Boyer, T.P.; Locarnini, R.A.; Garcia, H.E.; Mishonov, A.V. Global ocean heat content 1955-2008 in light of recently revealed instrumentation problems. Geophys. Res. Lett. 2009, 36, doi:10.1029/2008GL037155.

14. Levitus, S.; Antonov, J.I.; Boyer, T.P.; Baranova, O.K.; Garcia, H.E.; Locarnini, R.A.; Mishonov, A.V.; Reagan, J.R. World ocean heat content and thermosteric sea level change (0-2000 m) 1955-2010. Geophys. Res. Lett. 2012, 39, doi:10.1029/2012GL051106.

15. Johnson, G.C.; Lyman, J.M.; Willis, J.K.; Levitus, S.; Boyer, T.P.; Antonov, J.; Good S.A. Global Oceans: Ocean Heat Content. In State of the Climate in 2011; Blunden, J., Arndt, D.S., Eds.; Bulletin of the American Meteorological Society: Boston, MA, USA, 2012; Volume 93, S62-S65, doi:10.1175/2012BAMSStateoftheClimate.

16. Johnson, G.C.; Lyman, J.M.; Willis, J.K.; Levitus, S.; Boyer, T.P.; Antonov, J.; Good, S.A.; Domingues, C.M.; Wijffels, S.; Bindoff, N. Global Oceans: Ocean Heat Content. In State of the Climate in 2012. Blunden, J., Arndt, D.S., Eds.; Bulletin of the American Meteorological Society: Boston, MA, USA, 2013; Volume 94, S50-S53, doi:10.1175/2013BAMSStateoftheClimate.1.

17. Balmaseda, M.A.; Trenberth, K.E.; Kallen, E. Distinctive climate signals in reanalysis of global ocean heat content. Geophys. Res Lett. 2013, 40, 1-6.

18. Abraham, J.P.; Baringer, M.; Bindoff, N.L.; Boyer, T.; Cheng, L.J.; Church, J.A.; Conroy, J.L.; Domingues, C.M.; Fasullo, J.T.; Gilson, J.; et al. A review of global ocean temperature observations: Implications for ocean heat content estimates and climate change. Rev. Geophys. 2013, doi:10.1002/rog.20022.

19. Hansen, J.E.; Sato, M.; Kharecha, P.; von Schuckmann, K. Earth's energy imbalance and implications. Atmos. Chem. Phys. 2011, 11, 13421-13449.

20. Trenberth, K.E. An imperative for adapting to climate change: Tracking Earth's global energy. Curr. Opin. Environ. Sustain. 2009, 1, 19-27.

21. Nuccitelli, D.; Way, R.; Painting, R.; Church, J.; Cook, J. Comment on ocean heat content and Earth's radiation imbalance. II. Relation to climate shifts. Phys. Lett. A 2012, 376, 3466-3468.

22. Fasullo, J.T.; Trenberth, K.E. The annual cycle of the energy budget: Part I. Global mean and land-ocean exchanges. J. Clim. 2008, 21, 2297-2313.

23. Trenberth, K.E.; Fasullo, J.T. Tracking Earth's energy. Science 2010, 328, 316-317.

24. Pielke, R.A., Sr. A broader view of the role of humans in the climate system. Phys. Today 2008, 61, 54-55.

25. Myhre, G.; Highwood, E.J.; Shine, K.P.; Sordal, F. New estimates of radiative forcing due to well mixed greenhouse gases. Geophys. Res. Lett. 1998, 25, 2715-2718. 
(C) 2013 by the authors; licensee MDPI, Basel, Switzerland. This article is an open access article distributed under the terms and conditions of the Creative Commons Attribution license (http://creativecommons.org/licenses/by/3.0/). 